\title{
Enterococcus faecium and Enterococcus durans isolated from cheese: Survival in the presence of medications under simulated gastrointestinal conditions and adhesion properties
}

\author{
Daniel M. F. Amaral, Luana F. Silva, Sabrina N. Casarotti, Liane Caroline Sousa Nascimento, \\ and Ana Lúcia B. Penna ${ }^{1}$ \\ UNESP-Universidade Estadual Paulista, Instituto de Biociências, Letras e Ciências Exatas, Rua Cristóvão Colombo, 2265, \\ 15054-000 São José do Rio Preto, SP, Brazil
}

\section{ABSTRACT}

In this study, we evaluated the survival of Enterococcus faecium and Enterococcus durans, isolated from cheese, in the presence of medications and under simulated in vitro gastrointestinal conditions. The presence of genes encoding virulence factors, the susceptibility to antimicrobial agents, and adhesion properties were also assessed. Enterococcus faecium and E. durans both exhibited resistance to most of the tested medications but showed a large sensitivity to analgesics and antihypertensives; they also showed wide susceptibility to antimicrobial agents. Enterococcus durans SJRP29 had greater resistance to the presence of medications in comparison with the probiotic Lactobacillus acidophilus La-5. The strains, except for E. durans SJRP05, did not harbor virulence genes. Enterococcus durans SJRP14, SJRP17, and SJRP26 were sensitive to all tested antimicrobial agents. Enterococcus faecium was more stable during the simulation of gastrointestinal tract and showed greater viability. At the end of the assay, except for E. durans SJRP17, all strains showed high viability ( $>7 \log \mathrm{cfu} / \mathrm{mL}$ ). Enterococcus durans SJRP29 stood out from the other strains and was selected for further evaluation; it tolerated up to $3.0 \% \mathrm{NaCl}$ at 30 and $37^{\circ} \mathrm{C}$, besides having good adhesion properties (high values of auto-aggregation, co-aggregation, and hydrophobicity). Additionally, the microorganism did not show bile salt hydrolase activity or mucin degradation. These results encourage carrying out additional tests to evaluate the probiotic features by using in vitro dynamic models and in vivo tests before applying these strains to a food system.

Key words: lactic acid bacteria, tolerance to gastrointestinal condition, drug and antibiotic susceptibility, adhesion properties

Received May 25, 2016.

Accepted October 13, 2016.

${ }^{1}$ Corresponding author: analucia@ibilce.unesp.br

\section{INTRODUCTION}

Enterococcus spp. are lactic acid bacteria (LAB) whose natural habitat is the gastrointestinal (GI) tract of humans and animals. They are also found naturally in vegetables, plant material, and other food. They have specific characteristics, such as the ability to survive in moderately harsh conditions and to maintain viability after heating. Because of this tolerance, Enterococcus spp. seem to have a potential application in various food systems. Some evidence suggests that enterococci could have potential applications in the processing of certain fermented dairy products (Giraffa, 2003).

Several studies have evaluated the technological functionality of Enterococcus faecium, Enterococcus faecalis, and Enterococcus durans in combination with mesophilic and thermophilic LAB species (Litopoulou-Tzanetaki et al., 1993; Oumer et al., 2001; Sarantinopoulos et al., 2002). The presence of added enterococcal flora throughout ripening positively affected taste, aroma, color, structure, and the overall sensory profile of different types of cheese. The positive influence of the enterococci on dairy products seems to be due to their lipolytic activity, citrate utilization, and production of aromatic volatile compounds. Enterococci also have the ability to survive to adverse environmental conditions, such as extreme $\mathrm{pH}$, temperatures, and salinity. Consequently, they have been used as components of cheese starter cultures (Giraffa, 2003). Silva et al. (2015) concluded that these microorganisms guarantee the production of a high quantity of lactic acid, which contributes to rapid milk acidification and the production of several flavor and texture compounds.

Additionally, enterococci may produce antibacterial peptides (bacteriocins), generally called enterocins, which can improve products' shelf life and safety (Schirru et al., 2012; Todorov et al., 2011c, 2012, 2014; Favaro et al., 2014). Furthermore, E. faecium and E. faecalis strains have also been used as probiotics for humans and farm animals (Semedo et al., 2003), and 
the new strains show some synergistic actions with probiotic species, which may result in specific beneficial effects for consumers. However, such a role is still controversial, considering the studies on the determinants of virulence factors that have been performed on $E$. faecalis, E. faecium, and E. durans (including the food isolates). These studies indicated that these enterococci could be associated with enterococcal nosocomial infections and could harbor multiple antibiotic-resistance genes (Semedo et al., 2003; Favaro et al., 2014).

The beneficial effects of probiotic strains depend on the ability to survive natural host defenses and to multiply in the GI tract (Todorov and Dicks, 2008). The survival of probiotic bacteria under the harsh conditions of the GI tract is a complex process. It depends on the type of diet, availability of nutrients, interaction with GI bacteria, adhesion properties, and auto-aggregation and co-aggregation characteristics (Ahmadova et al., 2013; Todorov et al., 2011c). Therefore, the preliminary evaluation of probiotic microorganisms includes tolerance to GI tract (low $\mathrm{pH}$ and presence of bile salts), auto-aggregation, co-aggregation and hydrophobicity properties, presence of the adhesion genes, ability to hydrolyze lactose by $\beta$-galactosidase production and safety (absence of antibiotic resistance and virulence factors, and absence of mucolytic activity). After GI tract colonization, the microorganism needs to provide benefits to the host (Jeronymo-Ceneviva et al., 2014).

The survival of Enterococcus spp. under simulated GI tract conditions has been already evaluated by several authors, who showed that the strains were able to survive in the GI model, leading to their being considered good candidates for probiotics (Botes et al., 2008; Bhardwaj et al., 2010).

Changes in the diet, stress, or medications commonly used by people (analgesics, antiarrhythmics, antibiotics, antihistamines, proton pump inhibitors, antihypertensives, anti-inflammatories, contraceptives, and other commercial medicaments) may disrupt the microbial balance and cause the number of beneficial strains to decrease. Many individuals who consume probiotics might be simultaneously treating an illness or disorder. Todorov and Dicks (2008), Carvalho et al. (2009), Todorov et al. (2011a), Jeronymo-Ceneviva et al. (2014), and De Paula et al. (2015a) have shown that some medications interfere with the viability of the probiotic by inhibiting their therapeutic potential. As a consequence, a loss of probiotic effectiveness and uncontrolled proliferation of pathogenic bacteria may occur, causing diarrhea and other clinical disorders, such as inflammatory diseases, ulcerative colitis, and cancer (Vinderola et al., 2005; Galdeano et al., 2007).

De Paula et al. (2015a) evaluated the effect of medications in Leuconostoc mesenteroides ssp. mesen- teroides SJRP55 and found that among the 65 tested medications, 12 affected the growth of the bacteria. Most of them were analgesic and anti-inflammatory medications containing ibuprofen, butylscopolamine, metamizole, caffeine, orphenadrine citrate, and isometheptene mucate. Another study evaluated the effect of medicaments in LAB isolated from water buffalo mozzarella cheese. All LAB strains were able to survive in the presence of most commercial medications, and the strains were generally inhibited by drugs of the class of anti-inflammatories containing ibuprofen, ketoprofen, and diclofenac potassium (Jeronymo-Ceneviva et al., 2014).

Enterococcus spp. have intrinsic resistance to many antimicrobial agents, such as cephalosporin, $\beta$-lactams, and sulfonamides, and low levels of resistance to clindamycin and aminoglycosides. The resistance to chloramphenicol, erythromycin, clindamycin, aminoglycosides, tetracycline, $\beta$-lactam (due to the production of $\beta$-lactamase or penicillinase), fluoroquinolones, and glycopeptides are usually acquired (Dicks et al., 2009; Tan et al., 2014).

Currently, identifying novel potential probiotic strains, including Enterococcus spp., is important because each probiotic strain presents different mechanisms of action and different benefits to the host. Considering that Enterococcus spp. can also contribute to the technological and safety characteristics of fermented products, additional research is necessary to identify specific strains and specific characteristics that could also be beneficial for consumers (Rafter, 2004).

This study evaluated the survival of E. faecium and $E$. durans isolated from cheese in the presence of medications under simulated in vitro GI conditions, the adhesion properties of the bacteria, and bile salt hydrolase (BSH) activity. The study also determined the susceptibility of the bacteria to antimicrobial agents, the presence of virulence factors, and mucin degradation.

\section{MATERIALS AND METHODS}

\section{Isolation and Identification of Enterococcus spp.}

Ten strains of E. faecium and E. durans isolated from water buffalo mozzarella cheese samples, collected during storage in 3 independent trials, were used in this study. Based on the DNA gene sequencing, the strains SJRP20, SJRP28, and SJRP65 were previously identified as E. faecium, and the others (SJRP05, SJRP14, SJRP17, SJRP25, SJRP26, SJRP29, and SJRP68) were identified as E. durans (Silva et al., 2015).

Sterile glycerol (Vetec, Duque de Caxias, RJ, Brazil) was added to the cultures as a cryoprotectant, and cultures were stored in de Man, Rogosa, and Sharpe 
(MRS) broth (Difco Laboratories, Detroit, MI) at $-80^{\circ} \mathrm{C}$. At the time of analyses, the LAB strains were removed from the freezer and thawed at room temperature. To activate the bacteria, the enterococcal strains were inoculated in $10 \mathrm{~mL}$ of MRS broth $(2 \%, \mathrm{vol} / \mathrm{vol})$ and incubated at $37^{\circ} \mathrm{C} / 24 \mathrm{~h}$ under anaerobic conditions (von Mollendorff et al., 2007), provided by Anaerobac (Probac, São Paulo, SP, Brazil).

\section{Effect of Different Types of Medications on the Viability of Enterococcus Strains}

Sixty-two commercial medications, commonly consumed by people and belonging to different groups (analgesic, anti-inflammatory, antihypertensive, and so on), were selected and purchased in a local drugstore. For each medication, a tablet was dissolved in $5 \mathrm{~mL}$ of sterile water. The concentration of the substances in the dissolved medication is indicated in Table 1 . The sensitivity of enterococcal strains to these medications was evaluated according to Todorov et al. (2011a) and Carvalho et al. (2009). Before the assay, the Enterococcus strains were reactivated in MRS broth and incubated at $37^{\circ} \mathrm{C}$ for $24 \mathrm{~h}$. Then, $100 \mu \mathrm{L}$ of this culture was spread on the surface of MRS soft agar $(0.8 \%$, wt/vol) to achieve a population of $10^{6} \mathrm{cfu} / \mathrm{mL}$. The plates were maintained at room temperature for $1 \mathrm{~h}$. After this period, $10 \mu \mathrm{L}$ of each dissolved medication was added on the surface of MRS and incubated at $37^{\circ} \mathrm{C}$ for $24 \mathrm{~h}$. The plates with inhibition zones larger than $2 \mathrm{~mm}$ in diameter were subjected to the determination of the MIC. The MIC corresponded to the minimal concentration of medication resulting in inhibition halos of at least $2 \mathrm{~mm}$ in diameter (Todorov et al., 2011a). The commercial probiotic strain Lactobacillus acidophilus La-5 $\left(10^{6} \mathrm{cfu} / \mathrm{mL}\right.$, Chr. Hansen, Valinhos, SP, Brazil) was used as a reference strain. The percentage of resistance to the tested medications for each LAB was calculated by the relation between the number of medications to which the strain was resistant and the total number of tested medications. The experiments were performed in duplicate.

\section{Presence of Genes Encoding Virulence Factors, Vancomycin Resistance, and Biogenic Amine Production}

The investigation of the presence of genes encoding virulence factors, vancomycin resistance, and biogenic amine production by the E. faecium and E. durans strains was carried out using the primers and conditions described in Table 2. The amplified products were separated by electrophoresis on $1 \%$ (wt/vol) agarose gels in Tris/borate/EDTA (TBE) buffer. Gels were stained in TBE buffer containing $0.8 \mu \mathrm{g} / \mathrm{mL}$ ethidium bromide (Sigma-Aldrich, St. Louis, MO).

\section{Susceptibility to Antimicrobial Agents}

The susceptibility of 10 enterococcal strains to antimicrobial agents was tested by the agar disk diffusion test using antimicrobial agent disks (Oxoid, Sao Paulo, SP, Brazil): ampicillin $10 \mu \mathrm{g} /$ disk, linezolid $30 \mu \mathrm{g} /$ disk, ciprofloxacin $5 \mu \mathrm{g} /$ disk, chloramphenicol $30 \mu \mathrm{g} /$ disk, erythromycin $15 \mu \mathrm{g} /$ disk, fosfomycin $50 \mu \mathrm{g} /$ disk, gentamicin $10 \mu \mathrm{g} /$ disk, nitrofurantoin $300 \mu \mathrm{g} /$ disk, norfloxacin $10 \mu \mathrm{g} /$ disk, oxacillin $1 \mu \mathrm{g} /$ disk, penicillin 10 units/disk, streptomycin $300 \mu \mathrm{g} /$ disk, teicoplanin 30 $\mu \mathrm{g}$, tetracycline $30 \mu \mathrm{g}$, bacitracin $10 \mu \mathrm{g}$, and vancomycin $30 \mu \mathrm{g} /$ disk.

Reactivation of the strains was performed in MRS broth at $37^{\circ} \mathrm{C}$ for $24 \mathrm{~h}$, as previously described. A concentration of $10^{6} \mathrm{cfu} / \mathrm{mL}$ of each enterococcal strain was inoculated in MRS broth supplemented with $0.8 \%$ agar. After solidification, disks containing the antimicrobial agents were placed on the MRS agar surface, and incubation was at $37^{\circ} \mathrm{C}$ for $24 \mathrm{~h}$. The inhibition zones (in $\mathrm{mm}$ ) around each antimicrobial agents disk was evaluated, and a halo $>2 \mathrm{~mm}$ was considered positive (Todorov et al., 2011a). The experiments were performed in duplicate.

\section{Survival During the Simulation of GI Tract Conditions}

The strains of E. faecium and E. durans that maintained high viability in the presence of commercial drugs, were susceptible to the tested antimicrobial agents, and showed absence of virulence genes were inoculated into UHT whole milk and evaluated for survival in simulated GI tract conditions. The simulated gastric and enteric conditions were prepared according to Buriti et al. (2010), with modifications. Reactivation of the strains was performed in $10 \mathrm{~mL}$ of UHT whole milk at $37^{\circ} \mathrm{C}$ for $24 \mathrm{~h}$ to achieve a population of approximately $10^{9} \mathrm{cfu} / \mathrm{mL}$. After the incubation period, $10 \mathrm{~mL}$ of UHT whole milk containing the reactivated bacteria was diluted in $90 \mathrm{~mL}$ of $0.5 \%$ saline solution. This solution was divided into 9 tubes $(10 \mathrm{~mL}$ in each tube), corresponding to gastric phase, enteric phase I, and enteric phase II, in triplicate.

To simulate the gastric phase, pepsin solution $(3 \mathrm{~g} / \mathrm{L}$; Sigma-Aldrich) and lipase from Aspergillus niger (0.9 $\mathrm{mg} / \mathrm{L}$; Sigma-Aldrich) were added to the tubes and the 
Table 1. Different types of medications used in the evaluation of Enterococcus durans and Enterococcus faecium susceptibility

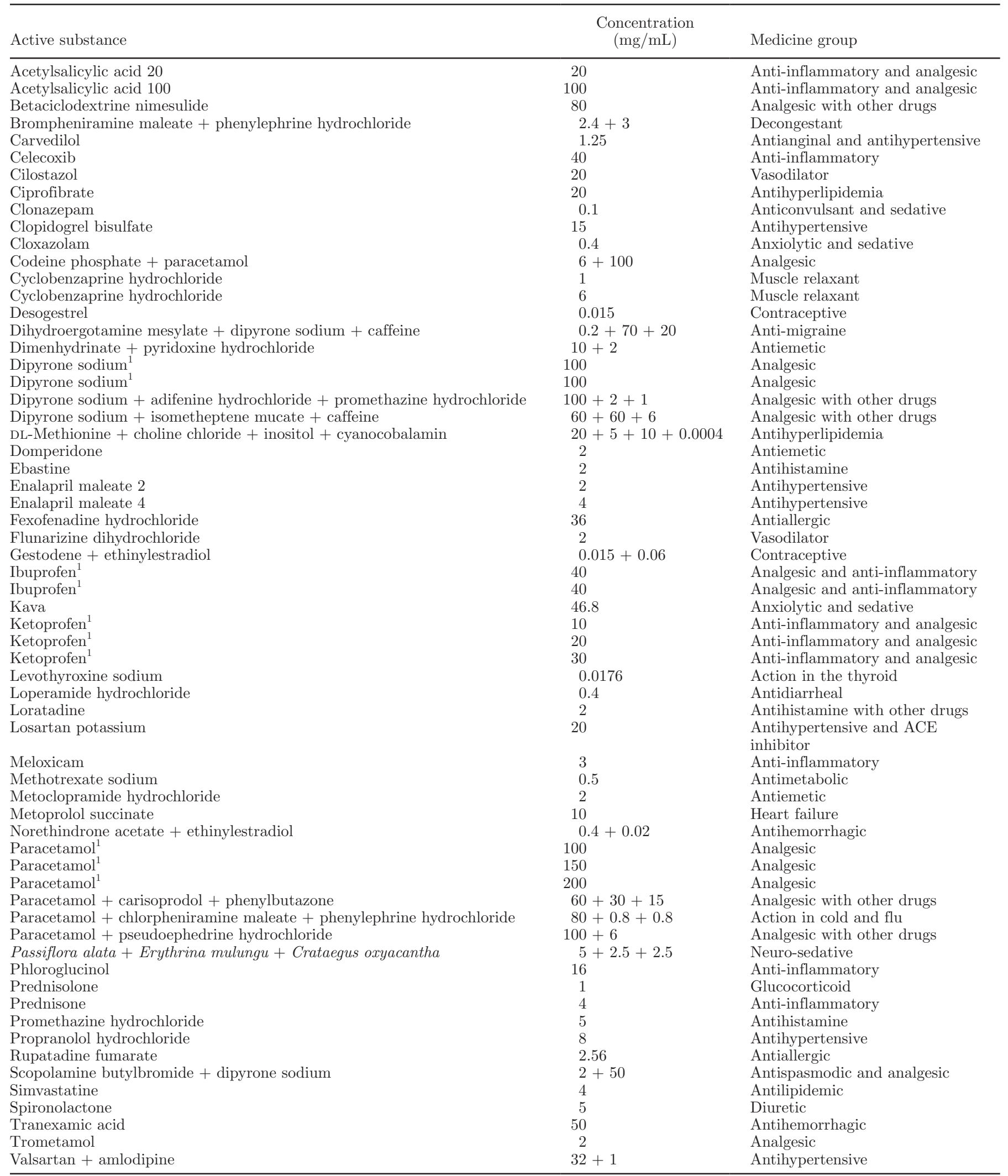

${ }^{1}$ Medications with the same name came from different commercial brands. 
Table 2. Primer sequences used in the investigation of presence of genes encoding virulence factors, vancomycin resistance, and biogenic amine production (Mannu et al., 2003; Vankerckhoven et al., 2004; de Las Rivas et al., 2005; Martín-Platero et al., 2009)

\begin{tabular}{|c|c|c|c|c|}
\hline Target & Gene $^{1}$ & Primer & $\begin{array}{c}\text { Annealing } \\
\text { temperature } \\
\left({ }^{\circ} \mathrm{C}\right)\end{array}$ & $\begin{array}{l}\text { Amplicon } \\
\text { size (bp) }\end{array}$ \\
\hline \multirow[t]{6}{*}{ Virulence } & gelE & $\begin{array}{l}\text { GEL 1: AGTTCATGTCTATTTTCTTCAC } \\
\text { GEL 2: CTTCATTATTTACACGTTTG }\end{array}$ & 56 & 402 \\
\hline & $h y l$ & $\begin{array}{l}\text { HYL n1: ACAGAAGAGCTGCAGGAAATG } \\
\text { HYL n2: GACTGACGTCCAAGTTTCCA }\end{array}$ & 53 & 276 \\
\hline & asa1 & $\begin{array}{l}\text { ASA 11: GCACGCTATTACGAACTATGA } \\
\text { ASA 12: TAAGAAAGAACATCACCACGA }\end{array}$ & 50 & 375 \\
\hline & cylA & $\begin{array}{l}\text { CYT I: ACTCGGGGATTGATAGGC } \\
\text { CYT IIb: GCTGCTAAAGCTGCGCTT }\end{array}$ & 52 & 688 \\
\hline & $e f a A$ & $\begin{array}{l}\text { EFA-AF: GCCAATTGGGACAGACCCTC } \\
\text { EFA-AR: CGCCTTCTGTTCCTTCTTTGGC }\end{array}$ & 57 & 688 \\
\hline & ace & $\begin{array}{l}\text { ACE-F: GAATTGAGCAAAAGTTCAATCG } \\
\text { ACE-R: GTCTGTCTTTTCACTTGTTTC }\end{array}$ & 48 & 1,008 \\
\hline \multirow{3}{*}{ Biogenic amines } & hdc2 & $\begin{array}{l}\text { 106: AAYTCNTTYGAYTTYGARAARGARG } \\
\text { 107: ATNGGNGANCCDATCATYTTRTGNCC }\end{array}$ & 50 & 534 \\
\hline & $t d c$ & $\begin{array}{l}\text { P1: CCRTARTCNGGNATAGCRAARTCNGTRTG } \\
\text { P2: GAYATNATNGGNATNGGNYTNGAYCARG }\end{array}$ & 55 & 924 \\
\hline & $o d c$ & $\begin{array}{l}\text { 3: GTNTTYAAYGCNGAYAARACNTAYTTYGT } \\
\text { 16: TACRCARAATACTCCNGGNGGRTANGG }\end{array}$ & 54 & 1,446 \\
\hline
\end{tabular}

${ }^{1} g e l E=$ gelatinase $h y l=$ hyaluronidase asa $1=$ aggregation substance esp $=$ enterococcal surface protein; $c y l A=$ cytolisin; efa $A=$ endocarditis antigen; $a c e=$ adhesion of collagen; $v a n A$ and $v a n B=$ vancomycin resistance; $h d c 1$ and $h d c 2=$ histidine decarboxylase; $t d c=$ tyrosine decarboxylase; odc $=$ ornithine decarboxylase.

$\mathrm{pH}$ was adjusted to 2.0 to 2.5 with $0.5 \mathrm{NHCl}$. To simulate the enteric phase I, the $\mathrm{pH}$ values of the samples were adjusted from 4.3 to 5.2 with the addition of alkaline solution containing pancreatin (1 g/L; Sigma-Aldrich) and bile salts (10 g/L; Sigma-Aldrich). To simulate the enteric phase II, the $\mathrm{pH}$ values of the samples were adjusted from 6.7 to 7.5 with the addition of the same solution, and the concentrations of pancreatin $(1 \mathrm{~g} / \mathrm{L}$; Sigma-Aldrich) and bile salts (10 g/L; Sigma-Aldrich) were adjusted. The samples were incubated for $120 \mathrm{~min}$ at $37^{\circ} \mathrm{C}$ under agitation of $150 \mathrm{rpm}$ between each step of the assay. After 30,120, 240, and $360 \mathrm{~min}$ of the beginning of the assay, 1-mL aliquots were collected from triplicate samples for the enumeration of viable cells. The serial dilutions were carried out using $0.1 \%$ (wt/vol) peptone water, and the bacteria were counted in MRS agar (Difco) applying the pour plate technique. The petri dishes were incubated at $37^{\circ} \mathrm{C}$ for $48 \mathrm{~h}$ in anaerobiosis provided by Anaerobac (Probac).

\section{Selection of Strains for Complementary Tests}

Strains that were simultaneously viable in the presence of medications, lacked antibiotic resistance and virulence genes, and showed high viability ( $>7 \log \mathrm{cfu} /$ $\mathrm{mL}$ ) under the simulated GI conditions were selected for complementary tests of tolerance to different $\mathrm{NaCl}$ concentrations, BSH activity, auto-aggregation and coaggregation, cell surface hydrophobicity, and absence of mucin degradation, which are essential for probiotic strains.

\section{Tolerance to $\mathrm{NaCl}$}

The cells' capacity to tolerate different $\mathrm{NaCl}$ concentrations was tested in vitro, according to Todorov et al. (2008). The selected strain was activated in MRS broth at $37^{\circ} \mathrm{C}$ for $18 \mathrm{~h}$ and cultivated in MRS broth adjusted to different $\mathrm{NaCl}$ concentrations $[0,0.5,1.0,3.0,5.0$, and 7.0 (wt/vol); Synth, Diadema, SP, Brazil). All tests were conducted in sterile flat-bottom 96-well micro titer plates (TPP, Trasadingen, Switzerland). Each well was filled with $180 \mu \mathrm{L}$ of modified MRS broth with $\mathrm{NaCl}$ and $20 \mu \mathrm{L}$ of culture. The optical density (OD) was measured at $600 \mathrm{~nm}\left(\mathrm{OD}_{600 \mathrm{~nm}}=0.2\right)$. The strain was incubated at 30 and $37^{\circ} \mathrm{C}$. The $\mathrm{OD}_{600} \mathrm{~nm}$ was recorded every hour for $12 \mathrm{~h}$. Experiments were performed in 3 different trials, in triplicate $(\mathrm{n}=9)$. 


\section{BSH Activity}

The BSH activity was evaluated according to Kumar et al. (2013), with some modifications. Briefly, the selected strain was activated in MRS broth at $37^{\circ} \mathrm{C}$ for 18 $\mathrm{h}$, and $10 \mu \mathrm{L}$ of the culture was spotted in MRS agar plates, supplemented with $0.5 \%$ (wt/vol) of sodium salt of taurodeoxycholic acid (TDCA; T0875, Sigma Aldrich) or taurocholic acid (TC; T4009, Sigma Aldrich), and $0.37 \mathrm{~g} / \mathrm{L}$ of $\mathrm{CaCl}_{2}$ (Vetec, Duque de Caxias, RJ, Brazil). Plates were incubated anaerobically at $37^{\circ} \mathrm{C}$ for $72 \mathrm{~h}$. The presence of white precipitated bile acid around spots was considered as a positive result. MRS plates without TDCA or TC were used as a negative control. Experiments were performed in 3 different trials, in triplicate $(\mathrm{n}=9)$.

\section{Auto-Aggregation, Co-Aggregation, and Hydrophobicity Assays}

The selected strain was activated in MRS broth at $37^{\circ} \mathrm{C}$ for $24 \mathrm{~h}$ and harvested by centrifugation $(7,000$ $\times g$ at $20^{\circ} \mathrm{C}$ for $10 \mathrm{~min}$ ), washed twice, and diluted in sterile saline solution $0.85 \%$. One milliliter of cell suspension was transferred to a 2-mL sterile Eppendorf tube to obtain the $\mathrm{OD}$ at $660 \mathrm{~nm}\left(\mathrm{OD}_{660 \mathrm{~nm}}=0.3\right)$, and the samples were incubated at 4,37 , and $42^{\circ} \mathrm{C}$. After 60 min, the cell suspension was centrifuged $\left(300 \times g, 20^{\circ} \mathrm{C}\right.$ for $2 \mathrm{~min}$ ) and the $\mathrm{OD}_{660 \mathrm{~nm}}$ of the supernatant was determined. The auto-aggregation was determined using Equation [1] (Todorov et al., 2011a), wherein $\mathrm{OD}_{0}$ refers to initial $\mathrm{OD}$ and $\mathrm{OD}_{60}$ refers to the $\mathrm{OD}$ value measured after 60 min:

$$
\text { Auto-aggregation }(\%)=\left[\left(\mathrm{OD}_{0}-\mathrm{OD}_{60}\right) / \mathrm{OD}_{0}\right] \times 100 \text {. [1] }
$$

For the co-aggregation assay, the strains and the indicating microorganisms L. fermentum (SJRP30) and L. casei (SJRP37) were cultivated in $10 \mathrm{~mL}$ of MRS broth and the strains of Listeria monocytogenes ATCC 7644 and Listeria innocua ATCC 33090 in brain heart infusion (BHI, Difco) at $30^{\circ} \mathrm{C}$. The cell preparation and the experimental protocol for the study of co-aggregation was the same used for auto-aggregation. The co-aggregation trials were performed in presence of 500 $\mu \mathrm{L}$ of selected LAB cells in combination with $500 \mu \mathrm{L}$ of the indicating microorganism cells in a sterile plastic cuvette. Co-aggregation was determined using Equation [2] (Todorov et al., 2011a), wherein $\mathrm{OD}_{0}$ refers to initial $\mathrm{OD}$ and $\mathrm{OD}_{60}$ refers to the $\mathrm{OD}$ value measured after $60 \mathrm{~min}$. All experiments were performed in 3 different trials, in triplicate $(\mathrm{n}=9)$ :

$$
\text { Co-aggregation }(\%)=\left[\left(\mathrm{OD}_{0}-\mathrm{OD}_{60}\right) / \mathrm{OD}_{0}\right] \times 100 \text {. [2] }
$$

The ability of the selected LAB cells surface to adhere to hydrophobic compounds was evaluated according to the methods reported by Todorov and Dicks (2008) and Doyle and Rosenberg (1995). The cells were centrifuged $\left(6,700 \times g\right.$ at $4^{\circ} \mathrm{C}$ for $\left.6 \mathrm{~min}\right)$, washed twice in phosphate buffer $0.1 M$, suspended in the same solution, and the $\mathrm{OD}_{580 \mathrm{~nm}}$ was measured $\left(\mathrm{OD}_{0}\right)$. Cell suspension $(1.5 \mathrm{~mL})$ was added to $1.5 \mathrm{~mL}$ of $\mathrm{n}$-hexadecane (Sigma Aldrich) and vortexed for $2 \mathrm{~min}$. The aqueous and organic phases were separated at room temperature for $30 \mathrm{~min}$. An aliquot of $1 \mathrm{~mL}$ of the aqueous phase was removed to determine the $\mathrm{OD}_{580 \mathrm{~nm}}$. The percentage of hydrophobicity was determined by Equation [3], wherein $\mathrm{OD}_{0}$ refers to the initial $\mathrm{OD}$ value and the $\mathrm{OD}_{30}$ refers to $O D$ value measured after $30 \mathrm{~min}$. The experiments were performed in 3 different trials, in triplicate $(n=9)$ :

$$
\text { Hydrophobicity }(\%)=\left[\left(\mathrm{OD}_{0}-\mathrm{OD}_{30}\right) / \mathrm{OD}_{0}\right] \times 100 .[3]
$$

\section{Mucin Degradation}

The selected LAB strain's capacity to degrade mucin was evaluated according to Peres et al. (2014) and Zhou et al. (2001). The cultures were activated in MRS broth and incubated at $37^{\circ} \mathrm{C}$ for 18 to $24 \mathrm{~h}$. Agar plates were prepared using the basal medium described by Zhou et al. (2001). Then, $10 \mu \mathrm{L}$ of the selected LAB strain was inoculated by spotting onto the surface of the agar plates, which were incubated at $37^{\circ} \mathrm{C}$ for $48 \mathrm{~h}$ anaerobically. After the incubation, plates were stained for 30 min with $0.1 \%$ amide black (wt/vol) (Merck Millipore Ltd., Cork, Ireland) prepared in $3.5 \mathrm{M}$ acetic acid and washed with $1.2 \mathrm{M}$ acetic acid. Mucin lyse zones were observed as discolored halos that indicated mucin degradation activity around the colonies. Escherichia coli ATCC 8739 and Salmonella enterica ssp. enterica serovar Typhimurium ATCC 14028 were used as a positive control and Lactobacillus rhamnosus GG (ATCC 53103) as a negative control. The experiments were performed in 2 different trials, in triplicate $(\mathrm{n}=6)$.

\section{Statistical Analysis}

The results of viability in the presence of drugs, susceptibility to antibiotics, tolerance to $\mathrm{NaCl}$, aggregation, co-aggregation, and hydrophobicity were analyzed through the average calculation and standard deviation. The results of survival during the simulation of GI tract conditions were examined by ANOVA in a completely randomized design in 3 replicates, using the software ESTAT version 2.0 (UNESP, Jaboticabal, SP, Brazil). Mean values were compared using the Tukey's test at 5\% significance level. 


\section{RESULTS AND DISCUSSION}

\section{Viability in the Presence of Medications}

Some people who consume probiotic foods may be simultaneously receiving medical treatments. Therefore, determining the effect of medications on the survival of potential probiotic strains is important. The 10 strains of E. faecium and E. durans were resistant to most of the medications (Table 3). Some medications had a strong effect on the Enterococcus strains, including analgesics (containing ibuprofen, paracetamol, and metamizole, which are available without medical prescription and commonly used by people of different ages, from babies to elderly people) and antihypertensive (containing valsartan, amlodipine, and enalapril maleate, often administered in continuous use for patients with coronary heart disease), anti-inflammatory, and antidiarrheal medications. In contrast, the antihypertensive and antidiarrheal drugs had a smaller effect on the growth of L. acidophilus La-5 (Table 3).

Almost all enterococcal strains and the probiotic strain of L. acidophilus La- 5 were inhibited by ibuprofen $(40 \mathrm{mg})$ and paracetamol $(150 \mathrm{mg} / \mathrm{mL})$. The strain $E$. durans SJRP29 was not inhibited by ibuprofen (40 mg/ $\mathrm{mL}$ ), and E. durans SJRP68 and E. faecium SJRP28 were not affected in the presence of paracetamol (Table 3 ). The interference of medications containing ibuprofen and diclofenac on the survival of probiotics may be a consequence of an increased concentration of potassium ions in the gastric contents because of the dissolution of diclofenac potassium in the stomach. The excess of potassium ions in the medium affects the viability of the bacterial cells (Carvalho et al., 2009; Todorov et al., 2011b).

None of the enterococcal strains had their growth affected by neuro-sedative (composed of Passiflora alata, Erythrina mulungu, and Crataegus oxyacantha), antimetabolic (methotrexate), antimigraine (composed of dihydroergotamine mesylate, dipyrone sodium, and caffeine), antiemetic (domperidone), and analgesics (dipyrone sodium and ketoprofen); however, growth of the probiotic strain L. acidophilus La-5 was inhibited by these medications. Additionally, the tolerance of enterococcal strains to methotrexate (2,4-diamino-N10methyl propylglutamic acid) was quite high, whereas $L$. acidophilus La-5 was inhibited by low MIC $(<0.01 \mathrm{mg})$; that is, it was able to inhibit the strain even at a very low concentration. The resistance to methotrexate is important because it is applied in different treatments (solid tumors, hematologic malignancies, multiple sclerosis, Crohn's disease, and rheumatoid arthritis), and enterococcal strains could be recommended for reducing the side effects of this medication on the GI microbiota.
Enterococcus durans SJRP05, SJRP17, SJRP29, and SJRP68 strains were less inhibited in the presence of medications (Table 3). Enterococcus durans SJRP29 showed optimal survival in the presence of medications (resistant to $85.48 \%$ of the tested medications). Despite being sensitive to paracetamol, it was resistant to other analgesics, such as ibuprofen and analgesic containing dipyrone sodium, adifenine hydrochloride, and promethazine hydrochloride, whereas the probiotic strain L. acidophilus La-5 was sensitive to all of them. Additionally, E. durans SJRP29 also presented notably high values for the MIC test compared with the other strains, which means that this strain was not inhibited by the tested medications even at high concentrations; the probiotic strain $L$. acidophilus La-5 was one of the most affected by the medications (sensitive to $27.4 \%$ of the tested medications, Table 3).

Because the medications may interfere with the viability of enterococci and thereby reduce the therapeutic effects of their probiotic properties, strains that maintain their viability for potential application in food or supplements must be selected. In addition, people who consume medications and probiotics simultaneously must be notified of this possibility.

Several studies have shown evidences of these medications' interferences in the probiotic properties and benefits of L. acidophilus (Todorov et al., 2011b); Enterococcus mundtii and Lactobacillus plantarum (Botes et al., 2008); Lactobacillus casei SJRP35, Leuconostoc citreum SJRP44, Lactobacillus delbrueckii ssp. bulgaricus SJRP57, and Leuconostoc mesenteroides ssp. mesenteroides SJRP58 (Jeronymo-Ceneviva et al., 2014); and Leuconostoc mesenteroides ssp. mesenteroides SJRP55 (De Paula et al., 2015a). In these studies, the effects of anti-inflammatories, diuretics, neuroleptics, analgesics, antipyretics, antifungals, contraceptives, and others were evaluated.

The natural intestinal bacteria may also be affected by the use of medications. The reduction of the number of beneficial bacteria naturally present in the intestine could result in an imbalance of the GI microbiota. This effect is based on the absorption of the medications through the GI tract, which depends on the breakdown by the enzymes present in the gut and released by the microbiota and on the interaction with food and beverages, which may decrease or increase the absorption. Considering this drug metabolism, further studies should be conducted to better understand the interactions between intestinal strains and medications. Moreover, physicians and pharmacists can better recommend which probiotic should be used simultaneously with medications in a specific case to prevent failure of the therapeutic effect of probiotics. 


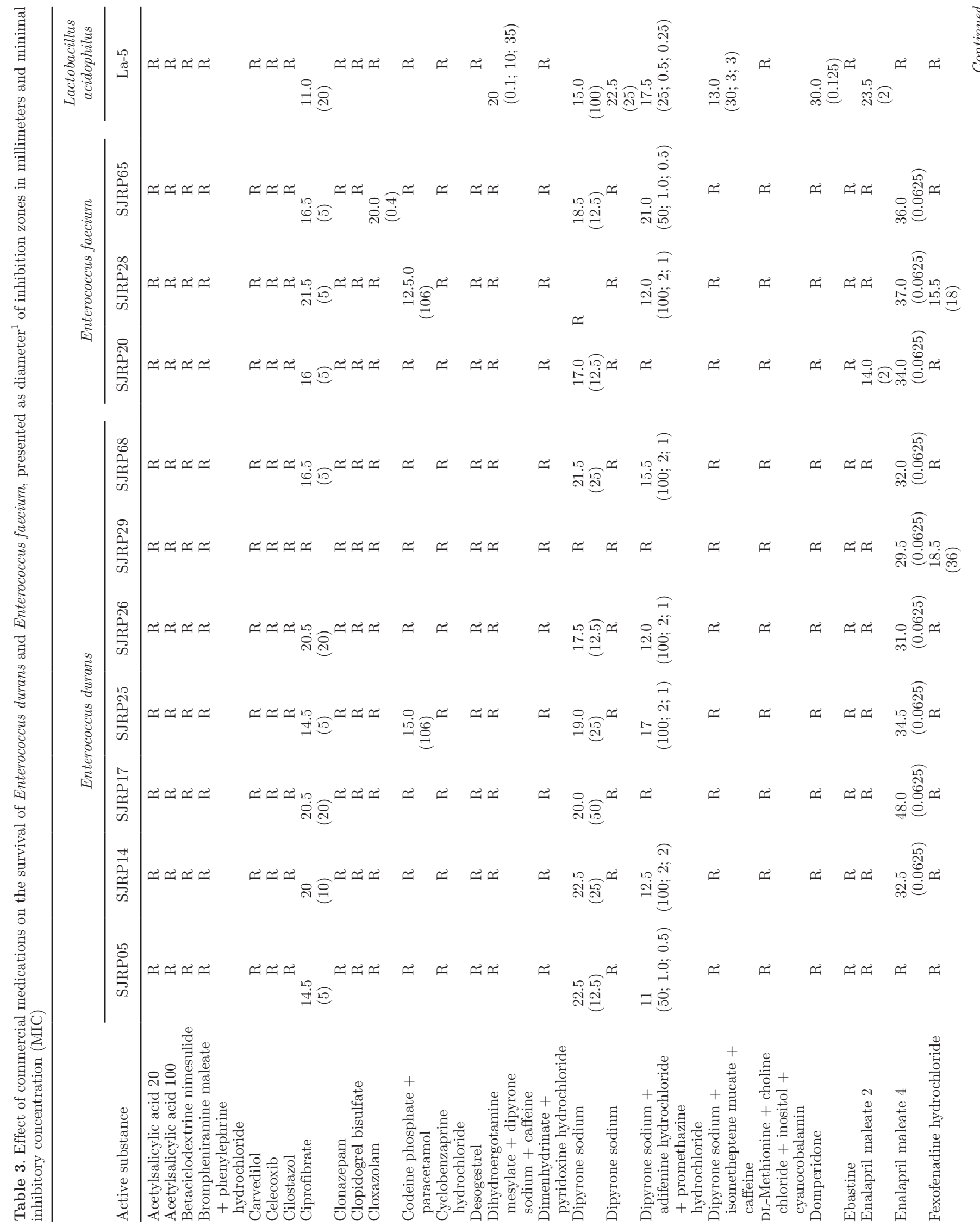




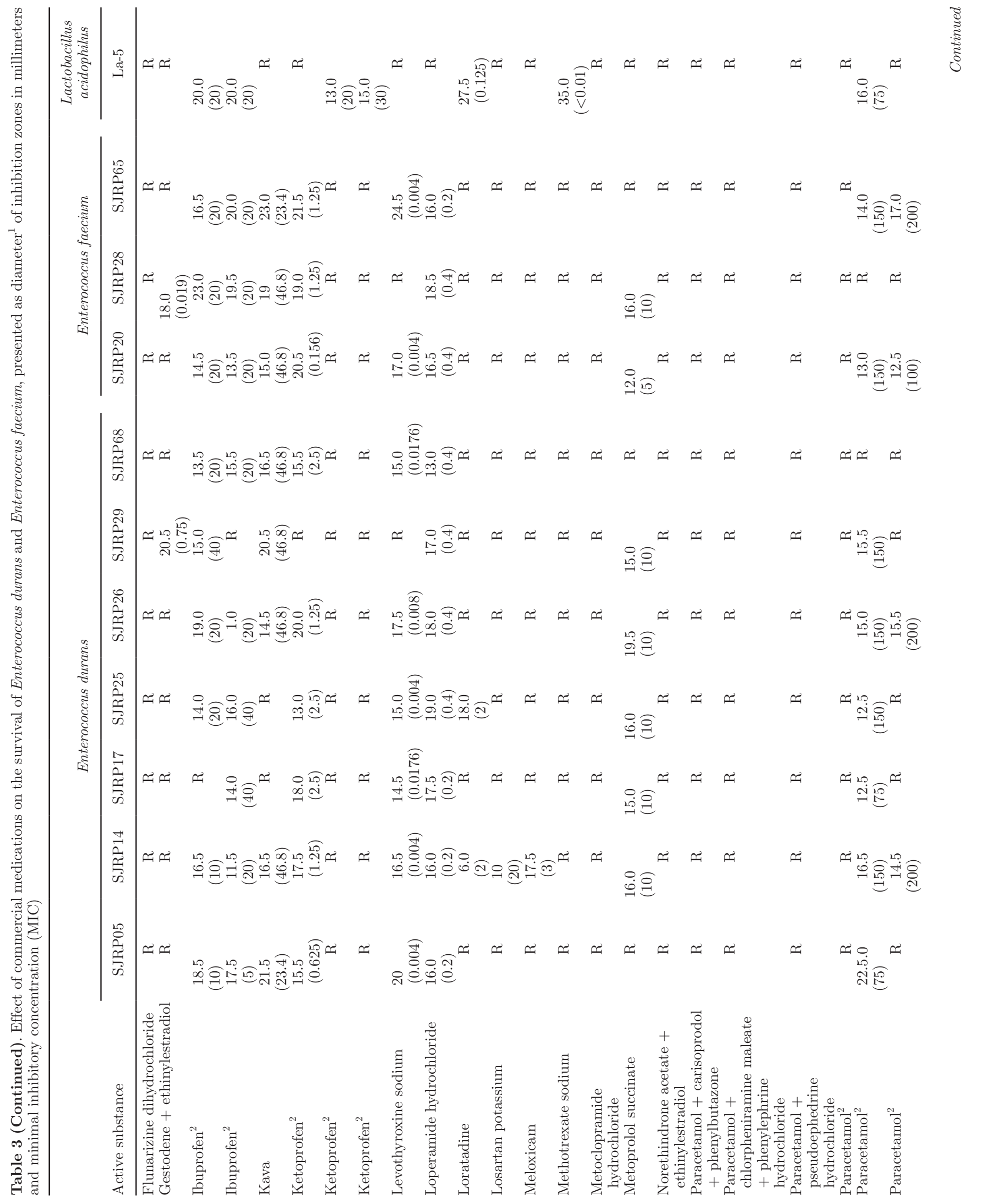




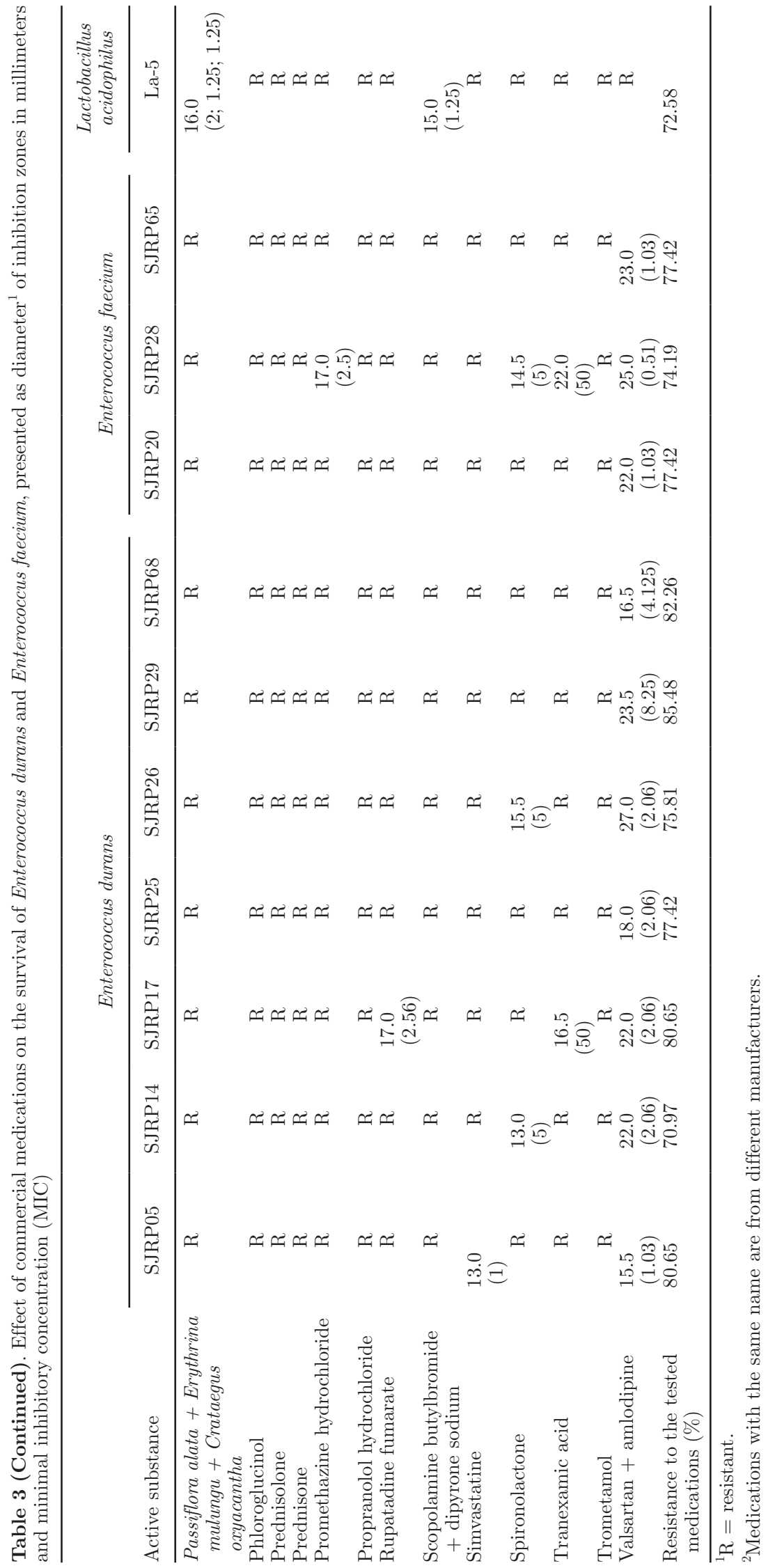


Table 4. Effect of antibiotics on Enterococcus durans and Enterococcus faecium ${ }^{1}$

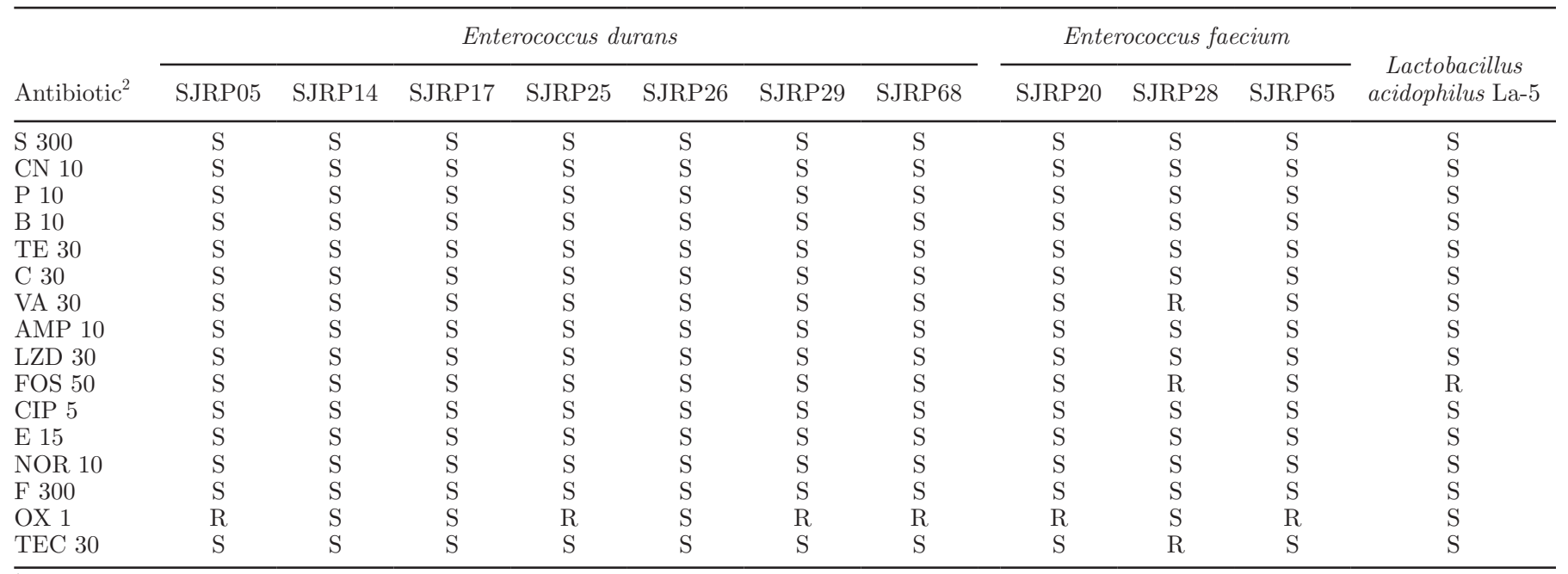

${ }^{1}$ Strains with inhibition halos $>2 \mathrm{~mm}$ were considered sensitive $(\mathrm{S})$, and strains with halos $<2 \mathrm{~mm}$ were considered resistant $(\mathrm{R})$.

${ }^{2} \mathrm{AMP} 10=$ ampicillin $10 \mu \mathrm{g}$; LZD $30=$ linezolid $30 \mu \mathrm{g}$; CIP $5=$ ciprofloxacin $5 \mu \mathrm{g}$; C $30=$ chloramphenicol $30 \mu \mathrm{g} /$ disk; E $15=$ erythromycin $15 \mu \mathrm{g} /$ disk; FOS $50=$ fosfomycin $50 \mu \mathrm{g} /$ disk; CN $10=$ gentamicin $10 \mu \mathrm{g} /$ disk; F $300=$ nitrofurantoin $300 \mu \mathrm{g} /$ disk; NOR $10=$ norfloxacin $10 \mu \mathrm{g} /$ disk; OX 1 = oxacillin $1 \mu \mathrm{g}$; P $10=$ penicillin 10 units/disk; S $300=$ streptomycin $300 \mu \mathrm{g} /$ disk; TEC $30=$ teicoplanin $30 \mu \mathrm{g} ; \mathrm{TE} 30=$ tetracycline $30 \mu \mathrm{g} /$ disk; B $10=$ bacitracin $10 \mu \mathrm{g}$; VA $30=$ vancomycin $30 \mu \mathrm{g} /$ disk.

\section{Sensitivity to Antimicrobial Agents}

Most of the enterococcal strains were sensitive to the majority of antimicrobial agents; however, resistance to the antibiotics oxacillin, teicoplanin, fosfomycin, and vancomycin was observed (Table 4). The strains E. durans SJRP05, SJRP25, SJRP29, and SJRP68 and E. faecium SJRP20 and SJRP65 were only resistant to oxacillin. The reference probiotic strain $L$. acidophilus La-5 showed resistance toward fosfomycin. In contrast, the guidance on the assessment of bacterial susceptibility to antimicrobials of human and veterinary importance, proposed by the European Food Safety Authority (2012) for gram-positive bacteria, does not include oxacillin, teicoplanin, and fosfomycin, probably because this kind of resistance is considered an intrinsic feature of LAB and chromosomally encoded.

Resistance to antimicrobial agents among different LAB isolated from fermented food (yogurt, fermented sausages, cheese) and commercial probiotic bacteria has already been documented (Lee et al., 2008; Drago et al., 2013; Morandi et al., 2013).

Werner et al. (2013) reported that enterococci are often resistant to antibiotics such as erythromycin, tetracycline, kanamycin, penicillin, and vancomycin. Drago et al. (2013) observed specific antibiotic resistance traits in many Italian and European probiotic strains. These traits may be a consequence of the acquisition of mobile genetic elements that encode antimicrobial resistance, leading to the spread of a variety of antimicrobial resistance determinants. Enterococcus strains isolated from retail shrimp presented high resistance to antimicrobial agents; more than half of all investigated isolates $(65.7 \%)$ were resistant to at least one class of antibiotics, and $16(45.7 \%)$ were classified as multidrug resistant. A high percentage of isolates were resistant to tetracycline $(48.6 \%)$, followed by tigecycline and fosfomycin (45.7\%; Chajẹcka-Wierzchowska et al., 2016).

The concern about resistance to antimicrobial agents is partly due to the indiscriminate use of this kind of medicine by human beings, agriculture, and livestock. Pathogenic bacteria, LAB, and opportunistic bacteria can then acquire or transmit resistance to antimicrobial agents and virulence genes via transposons and plasmids spread by conjugation or transformation (Grattepanche et al., 2008).

Enterococcus durans SJRP14, SJRP17, and SJRP26 strains were sensitive to all antimicrobial agents tested, including oxacillin, to which most strains were resistant. The other enterococcal strains showed similar results regarding susceptibility to antimicrobial agents. Morandi et al. (2013) also observed that none of the studied strains of Enterococcus lactis were classified as resistant to clinically important antibiotics such as ampicillin, erythromycin, penicillin G, tetracycline, and vancomycin. Furthermore, PCR-based detection did not identify any of the common genetic determinants for vancomycin, tetracycline, and erythromycin resistance.

Over the last years, enterococci have demonstrated a potential to harbor and transfer resistance genes. Courvalin (2006), Ogier and Serror (2008), Hollenbeck 
and Rice (2012), and more recently Sharma et al. (2014) published extensive and valuable reviews that summarize the multiple aspects of Enterococcus spp.: their role in dairy products (especially in cheese), the safety of commercial probiotic bacteria, the effect of opportunistic pathogens on human health, antibiotic multiresistance, the biochemistry of resistance, the genetics of resistance, and the potential for spreading resistance genes and virulence factors. These factors illustrate the controversial nature of this bacterial genus. Acquired resistance can be due to 2 distinct mechanisms: (1) mutations in endogenous (housekeeping) genes, in which case resistance is not transferable, and (2) acquisition of an exogenous resistance determinant from another bacterium by horizontal (lateral) gene transfer, in which case the gene can be transferable (Courvalin, 2006). The safety concern for such microorganisms arises from the possibility of the resistance spreading to harmful microorganisms or commensal gut microbiota. This transfer can be a major concern if the gene is carried by a mobile genetic element, especially a self-transferable plasmid or transposon. The resistance of E. faecium and E. faecalis to macrolides, tetracyclines, chloramphenicol, fosfomycin, rifampin, and quinolones is very common, and the resistance to glycopeptides, such as vancomycin and teicoplanin, is due to the synthesis of an alternative cell wall and depends on the phenotype. The mobile genetic elements (transposon Tn1546 and Inc.18 plasmids) are responsible for most gene mobility in enterococci and confer glycopeptide resistance (Hollenbeck and Rice, 2012).

Considering that enterococci can be used for a starter culture (starter) in many dairy products, especially because they produce particular sensory characteristics for the food products (Moraes et al., 2012), the concern is that enterococci could contribute to the horizontal spread of virulence factors to pathogenic or commensal bacteria present in the GI tract (De Paula et al., 2015b; Tejedor Junco et al., 2015). The microbial population found in the human intestine represents a huge reservoir of antimicrobial resistance genes, whose ingestion could influence the presence, establishment, and dynamics of resistance of bacteria to antimicrobial agents in the body (Gueimond et al., 2013). Therefore, the use of enterococci in foods, such as commercial starters and probiotic strains, should be possible on a case-by-case basis once studies establish their harmlessness or at least the lack of acquired antibiotic resistance genes and proven virulence factors (Ogier and Serror, 2008; Grattepanche et al., 2008; Favaro et al., 2015). Additionally, efforts must continue to prevent the development of antibiotic resistance and spread in enterococci (Hollenbeck and Rice, 2012).

\section{Virulence Factors}

Factors that may enhance the virulence of bacteria include antibiotic resistance determinants, cytolytic toxin, gelatinase, aggregation substance, extracellular superoxide production, and enterococcal surface protein (Tejedor Junco et al., 2015). The need for an effective risk assessment of new enterococcal strains is also strengthened by the concern for their presence and especially their use in food products (Semedo et al., 2003). In our study, except for E. durans SJRP05, the strains did not harbor virulence genes, such as gelE, cylA, hyl, asa1, esp, efaA, ace, vanA, vanB, hdc1, hdc2, $t d c$, and odc genes. Enterococcus durans SJRP05 presented gelatinase as a virulence gene. The gelE gene may play an essential role in host tissue invasion because it encodes for an extracellular zinc endopeptidase capable of hydrolyzing gelatin, collagen, casein, and other small biologically active peptides, and it can therefore contribute to virulence; this gene seems to be located in the chromosome (Semedo et al., 2003; Ribeiro et al., 2014).

The presence of virulence factors in Enterococcus spp. has been reported in the literature. Semedo et al. (2003) evaluated the occurrence of several virulence traits in enterococcal strains, including food and clinical isolates. Based on their virulence factors, enterococcal strains were grouped into 3 main clusters and 10 subclusters. The results showed that virulence traits occur in enterococci irrespective of their origin (human or animal hosts, food, and environment) and species allocation, suggesting that such genetic determinants may be a common trait in the genus Enterococcus. In general, food, commensal, and environmental strains harbor fewer virulence determinants; therefore, a low risk is involved in their use in food fermentations. However, Semedo et al. (2003) recommend screening for virulence traits and their cross-synergies, particularly for commercial starters, probiotic strains, and products to be used by high-risk population groups. Perin et al. (2014) studied the virulence, antibiotic resistance, and biogenic amines of bacteriocinogenic lactococci and enterococci isolated from goat milk. Among the 18 strains of enterococci, only 2 (E. durans GEn02 and E. durans GEn03) did not present any virulence genes. Favaro et al. (2014) investigated the safety concern of virulence genes for nonstarter E. faecium strains isolated from cheese and the occurrence of virulence genes was limited. Chajẹcka-Wierzchowska et al. (2016) reported that all of the enterococci isolated from retail shrimp carried between 5 and 9 tested virulence genes. The presence of esp (100\%), gelE (88.6\%), and efaA (77.1\%) genes and sex pheromones cpd (100\%), cob (94.3\%), and $c c f(94.3 \%)$ was more frequent in all of the tested 
Table 5. Population (log cfu/mL; mean $\pm \mathrm{SD}$ ) of Enterococcus durans and Enterococcus faecium after simulation of the gastrointestinal tract

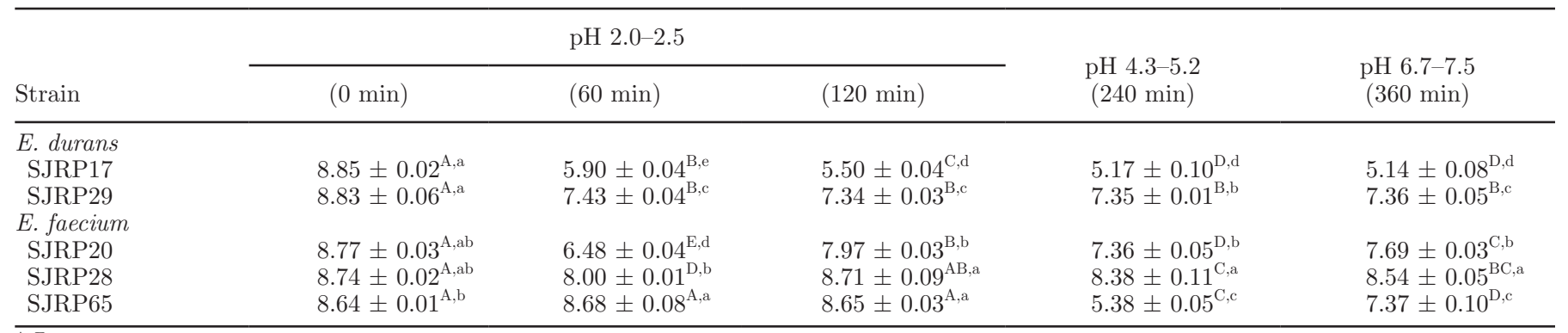

${ }^{\mathrm{A}-\mathrm{E}}$ Different letters in the same row indicate significant difference between the in vitro test analysis periods for the same strain $(P \leq 0.05)$. ${ }^{\mathrm{a}-\mathrm{e}}$ Different letters within the same column indicate significant difference among strains for the same period of in vitro test analysis $(P \leq 0.05$; $\mathrm{n}=3)$.

enterococci. Hassan and Belal (2016) evaluated the antibiotic resistance and virulence genes in enterococcal strains isolated from hospitals' environment. They reported that a total of $57.1 \%$ of E. faecium and $50 \%$ of $E$. durans isolates were resistant to multiple drugs; however, only 3 isolates of Enterococcus spp. harbored resistance genes ermB, tet $L$, and vanA.

Lactic acid bacteria (especially Enterococcus spp.) can present virulence genes that, when expressed in food products, represent hazards for consumers (Perin et al., 2014). The absence of virulence factors, as we found, is noteworthy because it supports the safety of enterococcal strains. The identification of LAB strains with virulence factors is relevant, and epidemiological studies should be conducted to monitor the presence and dissemination of resistance and virulence genes from enterococci to establish public health measures (Tejedor Junco et al., 2015).

Thus, safety characteristics must be properly assessed during the evaluation of LAB strains for them to be considered starters or biopreservative cultures. Furthermore, the absence of virulence factors can be used when selecting virulence-free microorganisms for a future application as functional starter cultures in preparation of fermented milk products (Perin et al., 2014).

\section{Assessment of Survival Under Simulated In Vitro GI Conditions}

Considering the results of viability in the presence of medications, susceptibility to antimicrobial agents, and absence of virulence factors, the E. durans strains SJRP17 and SJRP29 and E. faecium strains SJRP20, SJRP28, and SJRP65 were selected for probiotic potential analysis by a simulation test of GI tract, and their behavior is shown in Table 5 .

Enterococcus durans SJRP17 showed a decrease in its population in the very first $60 \mathrm{~min}$ of simulation, while E. faecium SJRP65 had a stable population only during the simulation of the gastric phase. In general, viability loss occurs in the gastric phase because of its lower $\mathrm{pH}$. In enteric phase $\mathrm{I}, \mathrm{pH}$ increases and it generally promotes population increases (i.e., recovery of viability). The strains E. durans SJRP29 and E. faecium SJRP20 showed a decrease in their populations during the early stages of the gastric phase. Normally, the $\mathrm{pH}$ profile of $\mathrm{H}^{+}$-ATPase enzyme and cytoplasmic membrane of $\mathrm{LAB}$ are associated with their tolerance to acidic conditions, which vary among species as well as according to exogenous conditions, including growth medium and incubation conditions (Madureira et al., 2011). However, the strains maintained their populations during the simulation of the enteric phase I and enteric phase II, which means that they can possibly overcome the harsh conditions of the GI tract and survive; this survival is one criterion to be fulfilled for a strain to be considered potential probiotic bacteria. Enterococcus faecium SJRP28 was the most stable during the simulation of GI tract, presenting a higher final population (Table 5). At the end of the assay, except for E. durans SJRP17, all strains showed high viability $(>7 \log \mathrm{cfu} / \mathrm{mL})$. Considering that probiotic food products must contain from 6 to $7 \mathrm{log} \mathrm{cfu} / \mathrm{mL}$ or cfu/g to produce their beneficial effects in the body (Nazzaro et al., 2012), if such strains are stable under GI conditions when used in food systems, they will probably be able to resist to acid $\mathrm{pH}$ and high concentrations of bile salts. Consequently, they may potentially be used in functional products or supplements. However, it is necessary to take into account that a food matrix plays an essential role in the strains' viability.

Additionally, it is important to emphasize that the in vitro trials involving tolerance of $\mathrm{pH}$ and bile salts cannot predict patterns of behavior in the human body. After the consumption of some foods, the stomach $\mathrm{pH}$ (around 1.2-2.0) becomes 3.0 to 4.0, depending on the food. After ingesting yogurt and fermented milk, the stomach $\mathrm{pH}$ increases considerably and can reach 5.0 (Cheng et al., 2004). Furthermore, the tolerance of GI 
transit has been found to vary among the strains (Vinderola and Reinheimer, 2003).

\section{Tolerance to $\mathrm{NaCl}$}

The presence of high concentrations of $\mathrm{NaCl}$ (5.0 and $7.0 \%$ ) was a limiting factor for the growth of E. durans SJRP29, whereas the incubation temperature had a more modest effect; however, the growth was slightly reduced at $37^{\circ} \mathrm{C}$. Moreover, E. durans SJRP29 tolerated up to $3.0 \% \mathrm{NaCl}$ at 30 and $37^{\circ} \mathrm{C}$ (Figure 1). Most LAB are halotolerant, which is an important characteristic for their use in dairy and fermented meat products (Penna et al., 2014), such as cheese and salami. Similar findings have been described in the literature. All LAB strains isolated from mozzarella cheese grew at $4 \% \mathrm{NaCl}$, while E. faecalis, Lactobacillus garvieae, Lactococcus lactis, and Streptococcus thermophilus showed absence of growth at 6.5 and $10.0 \% \mathrm{NaCl}$ (Silva, 2015).

\section{BSH Activity}

Enterococcus durans SJRP29 was not able to hydrolyze both taurocholic and taurodeoxycholic acids. Similarly, none of the lactobacilli strains, including $L$. casei, L. fermentum, and L. delbrueckii ssp. bulgaricus tested by Casarotti et al. (2016) and L. casei, L. fermentum, L. paracasei, L. plantarum, and L. pentosus tested by Solieri et al. (2014) were able to hydrolyze both TDCA and TC. However, the BSH enzyme is produced by several microorganisms and is efficient in the hydrolysis of glycoconjugate and tauroconjugate bile salts, as reported by Nascimento (2015) for L. fermentum SJRP42 and E. faecium SJRP20. Moser and Savage (2001) observed that L. buchneri JCM1069 was able to hydrolyze bile salts of TDCA; however, it was not able to hydrolyze the salts of TC.

\section{Auto-Aggregation, Co-Aggregation, and Hydrophobicity}

The aggregation ability can help probiotic cultures to adhere to and colonize the GI tract and to modulate the immune system (Ouwehand and Vesterlund, 2004). Enterococcus durans SJRP29 presented a high value of aggregation at the temperatures of $37^{\circ} \mathrm{C}(63.04 \%)$ and $42^{\circ} \mathrm{C}(59.05 \%)$, which is positive because aggregation is an important feature for biofilm formation; however, aggregation was only $33.61 \%$ at $4^{\circ} \mathrm{C}$. Similar results were observed for other LAB strains. Leuconostoc mesenteroides ssp. mesenteroides SJRP55 showed higher auto-aggregation at $30^{\circ} \mathrm{C}(85.64 \%)$, whereas when the tests were performed at $37^{\circ} \mathrm{C}$ and $5^{\circ} \mathrm{C}$, auto-aggregation values were $51.05 \%$ and $51.67 \%$, respectively (De Paula

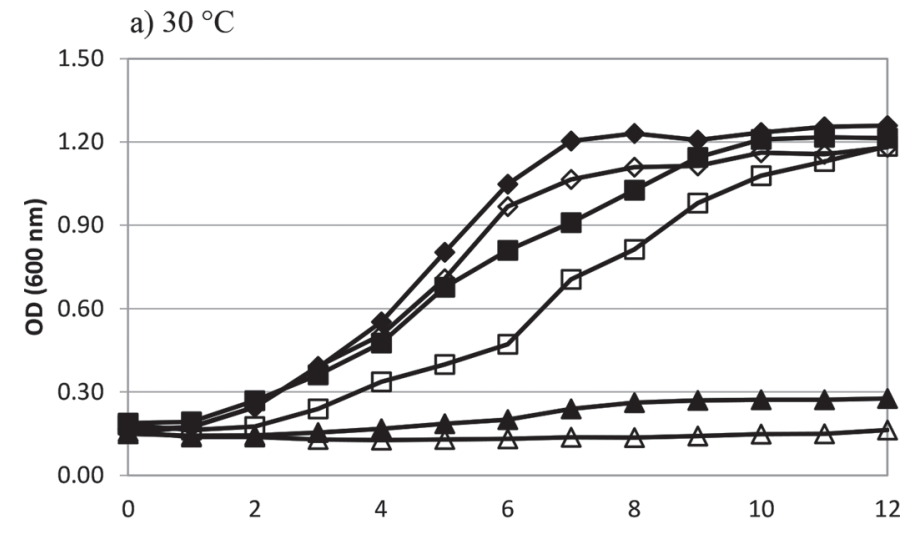

b) $37^{\circ} \mathrm{C}$

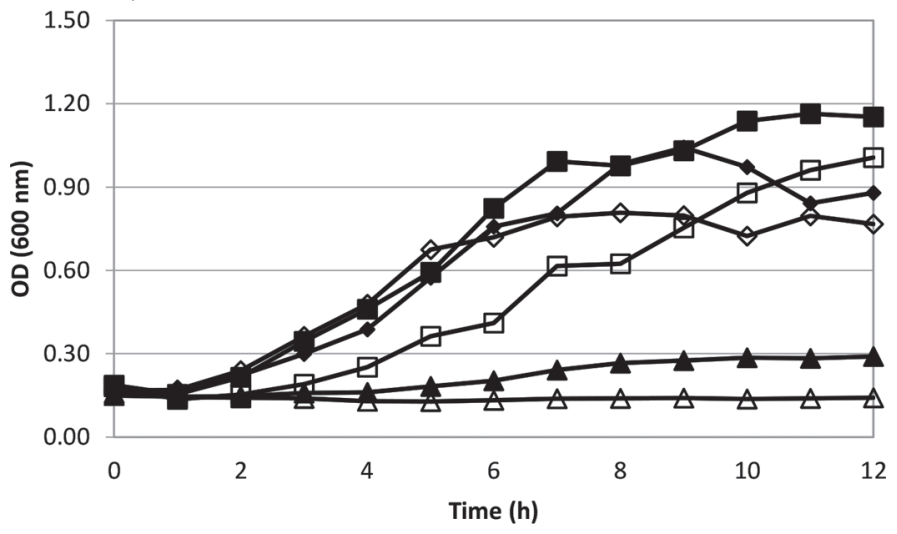

Figure 1. Growth of Enterococcus durans SJRP29 in de Man, Rogosa, and Sharpe broth with $0 \%(\diamond), 0.5 \%(\diamond), 1.0 \%(\square), 3.0 \%(\square)$, $5.0 \%(\boldsymbol{\Delta})$, or $7.0 \%(\Delta) \mathrm{NaCl}$ at 30 and $37^{\circ} \mathrm{C}$, shown as optical density $(\mathrm{OD} ; 660 \mathrm{~nm})$ measurements. The results are represented as an average of 9 readings.

et al., 2015a). In contrast, Todorov et al. (2011a) reported low values of auto-aggregation for LAB strains isolated from salmon, which ranged from $7.2 \%$ for $E$. faecium ET35 to $12.1 \%$ for E. faecium ET05.

Cell adhesion is a multistep process involving contact between the bacterial cell membrane and interacting surfaces. When adhesion occurs and the bacteria begin to colonize the GI tract, attachment of pathogens is prevented by blockage of the interaction with specific cell receptors or by inhibition of their fixation through enteric interactions (Kos et al., 2003).

Enterococcus durans SJRP29 also presented high values of co-aggregation with indicating microorganisms (Table 6). The co-aggregation between LAB and other cells, especially Listeria monocytogenes, may be considered a positive characteristic because it is one of the steps required for the elimination of nondesirable strains from the GI tract (Todorov and Dicks, 2008). However, the strain did not have an inhibitory effect against the indicating microorganisms (data not shown). This characteristic would be desirable for a 
Table 6. Auto-aggregation (\%), co-aggregation (\%), and cell surface hydrophobicity (\%) of Enterococcus durans SJRP29 $(\mathrm{n}=9)$

\begin{tabular}{lc}
\hline Characteristic & Mean $(\% \pm \mathrm{SD})$ \\
\hline Auto-aggregation at $4^{\circ} \mathrm{C}$ & $33.61 \pm 0.34$ \\
Auto-aggregation at $37^{\circ} \mathrm{C}$ & $63.04 \pm 0.19$ \\
Auto-aggregation at $42^{\circ} \mathrm{C}$ & $59.05 \pm 0.45$ \\
Co-aggregation with Lactobacillus fermentum SJRP30 & $51.71 \pm 0.16$ \\
Co-aggregation with Lactobacillus casei SJRP37 & $67.82 \pm 0.19$ \\
Co-aggregation with Listeria innocua ATCC 33090 & $73.25 \pm 0.33$ \\
Co-aggregation with Listeria monocytogenes ATCC 15313 & $44.01 \pm 0.32$ \\
Hydrophobicity & $96.53 \pm 0.14$ \\
Mucin degradation & Negative \\
\hline
\end{tabular}

better competition between E. durans SJRP29 and pathogenic microorganisms that could be present in the diverse and complex microbiota of the human intestinal tract. Although no inhibitory activity was detected for E. durans SJRP29, the bacteria can compete with pathogenic microorganisms in several ways, such as for space or nutrients. Furthermore, LAB can improve the intestinal response, and when used in food production, they can improve sensory value and also be used as a strategy for food biopreservation (Kos et al., 2008).

In the present study, the selected strain showed a high level of cell surface hydrophobicity (96.53\%, Table $6)$, measured using the interaction with n-hexadecane to simulate the ability to adhere to the intestinal epithelium. The observed result was higher than that reported in the literature for strains isolated from smoked salmon, previously identified as bacteriocin producers: L. fermentum $(78.9 \%)$, L. curvatus $(61.9-64.6 \%), L$. delbrueckii (43.7\%), Pediococcus acidilactici (51.3\%), and L. rhamnosus GG (53.3\%) (Todorov et al., 2011b); Leuconostoc paramesenteroides isolated from Cheddar cheese (46.11\%) (Shobharani and Agrawal, 2011); and Leuconostoc mesenteroides ssp. mesenteroides SJRP55 $(59.12 \%)$, isolated from mozzarella cheese (De Paula et al., 2015a). Additionally, cell surface hydrophobicity is strain specific, and the presence of different nutrients or carrier food matrices may affect the expression of adhesion genes in the microorganisms (Raghavendra and Halami, 2009).

\section{Mucin Degradation}

Enterococcus durans SJRP29 as well as L. rhamnosus GG (ATCC 53103) (negative control) did not show mucinolytic activity in either type of tested media [with or without $3 \%$ (wt/vol) of glucose] and was considered safe with regard to the maintenance of the mucosal integrity of the intestine. Conversely, S. enterica ssp. enterica serovar Typhimurium ATCC 14028 (positive control) was able to degrade mucin in vitro in a medium in which mucin was the only energy source (data not shown). These findings are in agreement with previous stud- ies that investigated mucin degradation of E. faecium and E. faecalis bacteria (Abe et al., 2010). Any damage or disturbance of the mucin layer will compromise the defense function of the host mucosa (Zhou et al., 2001).

For the probiotic candidate E. durans SJRP29 to be used in functional food or supplements, it is essential to evaluate their additional characteristics, such as cytotoxicity and immunomodulatory properties. Furthermore, it is also important to carry out studies using in vitro dynamic models, such as simulator of the human intestinal microbial ecosystem, and in vivo tests before applying these strains to a food system.

\section{CONCLUSIONS}

Enterococcus faecium and E. durans both showed resistance to most of the tested medications but had substantial sensitivity to analgesics and antihypertensives; they also presented a wide susceptibility to antimicrobial agents. Enterococcus durans SJRP29 exhibited more resistance to the presence of medications than the probiotic L. acidophilus La-5. The strains submitted to an evaluation simulating the GI system expressed tolerance to $\mathrm{pH}$ and bile, with high viability. Enterococcus durans SJRP29 was selected for further evaluation and tolerated up to $3.0 \% \mathrm{NaCl}$ at 30 and $37^{\circ} \mathrm{C}$; it also presented good adhesion properties (high values of auto-aggregation, co-aggregation, and hydrophobicity). Additionally, the microorganism did not show BSH activity and mucin degradation. Enterococcus durans SJRP29 is considered safe and has good potential for application in functional food or supplements. These results encourage us to carry out additional tests to evaluate the probiotic features using in vitro dynamic models and in vivo tests before applying these strains to a food system.

\section{ACKNOWLEDGMENTS}

The authors thank Fundação de Amparo à Pesquisa do Estado de São Paulo (FAPESP, Brazil, Projects N ${ }^{\circ}$ 2011/11922-0, 2012/09541-1 and 2014/02131-8) and 
Coordenação de Aperfeiçoamento de Pessoal de Nível Superior (CAPES, Brazil) for the financial support. The authors also thank Simone Quintão da Silva for her assistance with the virulence factors assay.

\section{REFERENCES}

Abe, F., M. Muto, T. Yaeshima, K. Iwatsuki, H. Aihara, Y. Ohashi, and T. Fujisawa. 2010. Safety evaluation of probiotic bifidobacteria by analysis of mucin degradation activity and translocation ability. Anaerobe 16:131-136.

Ahmadova, A., S. D. Todorov, Y. Choiset, H. Rabesona, T. M. Zadi, A. Kuliyev, B. D. G. M. Franco, J. Chobert, and T. Haertle. 2013. Evaluation of antimicrobial activity, probiotic properties and safety of wild strain Enterococcus faecium AQ71 isolated from Azerbaijani Motal cheese. Food Control 30:631-641.

Bhardwaj, A., H. Gupta, S. Kapila, G. Kaur, S. Vij, and R. K. Malik. 2010. Safety assessment and evaluation of probiotic potential of bacteriocinogenic Enterococcus faecium KH 24 strain under in vitro and in vivo conditions. Int. J. Food Microbiol. 141:156-164.

Botes, M., C. A. Van Reenen, and L. M. T. Dicks. 2008. Evaluation of Enterococcus mundtii ST4SA and Lactobacillus plantarum 423 as probiotics by using a gastro-intestinal model with infant milk formulations as substrate. Int. J. Food Microbiol. 128:362-370.

Buriti, F. C. A., I. A. Castro, and S. M. I. Saad. 2010. Viability of Lactobacillus acidophilus in symbiotic guava mousses and its survival under in vitro simulated gastrointestinal conditions. Int. J. Food Microbiol. 137:121-129.

Carvalho, K. G., M. F. Kruger, D. N. Furtado, S. D. Todorov, and B. D. G. M. Franco. 2009. Evaluation of the role of environmental factors in the human gastrointestinal tract on the behaviour of probiotic cultures Lactobacillus casei Shirota and Lactobacillus casei LC01 by the use of a semi-dynamic in vitro model. Ann. Microbiol. 59:439-445

Casarotti, S. N., B. M. Carneiro, S. D. Todorov, and A. L. B. Penna. 2016. Probiotic and safety characterization of Lactobacillus isolated from water-buffalo mozzarella cheese. Page 166 in Abstracts Book Food Micro 2016, Dublin. University College Dublin, Ireland.

Chajẹcka-Wierzchowska, W., A. Zadernowska, and L. ŁaniewskaTrokenheim. 2016. Virulence factors, antimicrobial resistance and biofilm formation in Enterococcus spp. isolated from retail shrimps. Lebensm. Wiss. Technol. 69:117-122.

Cheng, G., A. N. Feng, Z. Mei-Juan, S. J. Xiu-Hua Hao, and H. E. Yun-Xia. 2004. Time- and pH-dependent colon-specific drug delivery for orally administered diclofenac sodium and 5-aminosalicylic acid. World J. Gastroenterol. 10:1769-1774.

Courvalin, P. Antibiotic resistance: The pros and cons of probiotics 2006. Dig. Liver Dis. 38(2):261-265.

de Las Rivas, B., A. Marcobal, and R. Muñoz. 2005. Improved multiplex-PCR method for the simultaneous detection of food bacteria producing biogenic amines. FEMS Microbiol. Lett. 244:367-372.

De Paula, A. T., A. B. Jeronymo-Ceneviva, L. F. Silva, S. D. Todorov, B. D. G. M. Franco, and A. L. B. Penna. 2015a. Leuconostoc mesenteroides SJRP55: A potential probiotic strain isolated from Brazilian water buffalo Mozzarella cheese. Ann. Microbiol. 65:899-910.

De Paula, A. T., A. B. Jeronymo-Ceneviva, S. D. Todorov, and A. L. B. Penna. 2015b. The two faces of Leuconostoc mesenteroides in food systems. Food Rev. Int. 31:147-171.

Dicks, L. M. T., S. D. Todorov, and B. D. G. M. Franco. 2009. Current status of antibiotic resistance in lactic acid bacteria. Pages 379-424 in Antibiotic Resistance: Causes and Risk Factors, Mechanisms and Alternatives. A. R. Bonilla and K. P. Muniz, ed. Nova Sci. Pub. Inc., New York, NY.

Doyle, R. J., and M. Rosenberg. 1995. Measurement of microbial adhesion to hydrophobic substrates. Methods Enzymol. 253:542-550.

Drago, L., R. Mattina, E. De Vecchi, and M. Toscano. 2013. Phenotypic and genotypic antibiotic resistance in some probiotics proposed for medical use. Int. J. Antimicrob. Agents 41:396-397.
European Food Safety Authority. 2012. Guidance on the assessment of bacterial susceptibility to antimicrobials of human and veterinary importance. EFSA J. 10:2740. Accessed Jan. 15, 2016. http:// www.efsa.europa.eu/efsajournal/en/efsajournal/pub/2740.

Favaro, L., M. Basaglia, S. Casella, I. Hue, X. Dousset, B. D. G. de Melo Franco, and S. D. Todorov. 2014. Bacteriocinogenic potential and safety evaluation of non-starter Enterococcus faecium strains isolated from home made white brine cheese. Food Microbiol. $38: 228-239$.

Favaro, L., A. L. B. Penna, and S. D. Todorov. 2015. Bacteriocinogenic LAB from cheeses-Application in biopreservation? Trends Food Sci. Technol. 41:37-48.

Galdeano, C. M., A. de Moreno de LeBlanc, G. Vinderola, M. E. Bibas Bonet, and G. Perdigón. 2007. Proposed model: Mechanisms of immunomodulation induced by probiotic bacteria. Clin. Vaccine Immunol. 14:485-492.

Giraffa, G. 2003. Functionality of enterococci in dairy products. Int. J. Food Microbiol. 88:215-222.

Grattepanche, F., S. Miescher-Schwenninger, L. Meile, and C. Lacroix. 2008. Recent developments in cheese cultures with protective and probiotic functionalities. Dairy Sci. Technol. 88:421-444.

Gueimond, M., B. Sánchez, C. G. de los Reyes-Gavilán, and A. Margolles. 2013. Antibiotic resistance in probiotic bacteria. Front. Microbiol. 4:1-6.

Hassan, M. M., and E. S. B. Belal. 2016. Antibiotic resistance and virulence genes in enterococcus strains isolated from different hospitals in Saudi Arabia. Biotechnol. Biotechnol. Equip. 30:726-732. https://doi.org/10.1080/13102818.2016.1184992.

Hollenbeck, B. L., and L. B. Rice. 2012. Intrinsic and acquired resistance mechanisms in Enterococcus. Virulence 3:421-433.

Jeronymo-Ceneviva, A. B., A. T. de Paula, S. D. Todorov, B. G. M. Franco, and A. L. B. Penna. 2014. Potential beneficial properties of lactic acid bacteria isolated from water-buffalo Mozzarella cheese. Probiotics Antimicrob. Proteins 6:141-156.

Kos, B., J. Suskovic, J. Beganovic, K. Gjuracic, J. Frece, C. Iannaccone, and F. Canganella. 2008. Characterization of the three selected probiotic strains for the application in food industry. World J. Microbiol. Biotechnol. 24:699-707.

Kos, B., J. Susković, S. Vuković, M. Simpraga, J. Frece, and S. Matosić. 2003. Adhesion and aggregation ability of probiotic strain Lactobacillus acidophilus M92. J. Appl. Microbiol. 94:981-987.

Kumar, A., M. Kumar, M. Ghosh, and A. Ganguli. 2013. Modeling in vitro cholesterol reduction in relation to growth of probiotic Lactobacillus casei. Microbiol. Immunol. 57:100-110.

Lee, K., M. Lee, and Y. Lee. 2008. Safety assessment of commercial Enterococcus probiotics in Korea. J. Microbiol. Biotechnol. 18:942-945.

Litopoulou-Tzanetaki, E., N. Tzanetakis, and A. Vafopoulou-Mastrojiannaki. 1993. Effect of type of lactic starter on microbiological, chemical and sensory characteristics of Feta cheese. Food Microbiol. 10:31-41.

Madureira, A. R., M. Amorim, A. M. Gomes, M. E. Pintado, and F. X. Malcata. 2011. Protective effect of whey cheese matrix on probiotic strains exposed to simulated gastrointestinal conditions. Food Res. Int. 44:465-470.

Mannu, L., A. Paba, E. Daga, R. Comunian, S. Zanetti, I. Dupré, and L. A. Sechi. 2003. Comparison of the incidence of the virulence determinants and antibiotic resistance between Enterococcus faecium of dairy, animal and clinical origin. Int. J. Food Microbiol. 88:291-304

Martín-Platero, A. M., E. Valdivia, M. Maqueda, and M. MartínezBueno. 2009. Characterization and safety evaluation of enterococci isolated from Spanish goats' milk cheese. Int. J. Food Microbiol. 132:24-32.

Moraes, P. M., L. M. Perin, S. D. Todorov, A. Silva Jr., B. D. Franco, and L. A. Nero. 2012. Bacteriocinogenic and virulence potential of Enterococcus isolates obtained from raw milk and cheese. J. Appl. Microbiol. 113:318-328.

Morandi, S., T. Silvetti, and M. Brasca. 2013. Biotechnological and safety characterization of Enterococcus lactis, a recently described species of dairy origin. Antonie van Leeuwenhoek 103:239-249. 
Moser, S. A., and D. C. Savage. 2001. Bile salt hydrolase activity and resistance to toxicity of conjugated bile salts are unrelated properties in lactobacilli. Appl. Environ. Microbiol. 67:3476-3480.

Nascimento, L. C. S. 2015. Potencial probiótico e produção de substâncias antimicrobianas por culturas láticas e aplicação em leites fermentados. [Probiotic potential and production of antimicrobial compounds by lactic acid bacteria and application in fermented milk]. Qualification Exam for Thesis. Department of Food Engineering and Technology, São Paulo State University, São José do Rio Preto, Brazil.

Nazzaro, F., F. Fratianni, B. Nicolaus, A. Poli, and P. Orlando. 2012. The prebiotic source influences the growth, biochemical features and survival under simulated gastrointestinal conditions of the probiotic Lactobacillus acidophilus. Anaerobe 18:280-285.

Ogier, J. C., and P. Serror. 2008. Safety assessment of dairy microorganisms: The Enterococcus genus. Int. J. Food Microbiol. 126:291301.

Oumer, B. A., P. Gaya, E. Fernandez-Garcia, R. Marciaca, S. Garde, M. Medina, and M. Nunez. 2001. Proteolysis and formation of volatile compounds in cheese manufactured with a bacteriocins producing adjunct culture. J. Dairy Res. 68:117-129.

Ouwehand, A. C., and S. Vesterlund. 2004. Antimicrobial components from lactic acid bacteria. Pages 375-396 in Lactic Acid Bacteria Microbiological and Functional Aspects. S. Salminen, A. von Wright, and A. Ouwehand, ed. Marcel Dekker, New York, NY.

Penna, A. L. B., A. T. de Paula, S. N. Casarotti, L. F. Silva, V. R. Diamantino, and S. D. Todorov. 2014. Overview of the functional lactic acid bacteria in the fermented milk products. Pages 113-148 in Beneficial Microbes in Fermented and Functional Foods. R. V. Ravishankar and B. A. Jamuna, ed. CRC Press, Boca Raton, FL.

Peres, C. M., M. Alves, A. Hernandez-Mendoza, L. Moreira, S. Silva, M. R. Bronze, L. Vilas-Boas, C. Peres, and F. X. Malcata. 2014. Novel isolates of lactobacilli from fermented Portuguese olive as potential probiotics. Lebensm. Wiss. Technol. 59:234-246.

Perin, L. M., R. O. Miranda, S. D. Todorov, B. D. G. M. Franco, and L. A. Nero. 2014. Virulence, antibiotic resistance and biogenic amines of bacteriocinogenic lactococci and enterococci isolated from goat milk. Int. J. Food Microbiol. 185:121-126.

Rafter, J. 2004. The effects of probiotics on colon cancer development. Nutr. Res. Rev. 17:277-284.

Raghavendra, P., and P. M. Halami. 2009. Screening, selection and characterization of phytic acid degrading lactic acid bacteria from chicken intestine. Int. J. Food Microbiol. 133:129-134.

Ribeiro, S. C., M. C. Coelho, S. D. Todorov, B. D. G. M. Franco, M. L. E. Dapkevicius, and C. C. G. Silva. 2014. Technological properties of bacteriocin-producing lactic acid bacteria isolated from Pico cheese an artisanal cow's milk cheese. J. Appl. Microbiol. 116:573-585

Sarantinopoulos, P., G. Kalantzopoulos, and E. Tsakalidou. 2002. Effect of Enterococcus faecium on microbiological, physicochemical and sensory characteristics of Greek Feta cheese. Int. J. Food Microbiol. 76:93-105.

Schirru, S., S. D. Todorov, L. Favaro, N. P. Mangia, M. Basaglia, S. Casella, R. Comunian, B. G. M. Franco, and P. Deiana. 2012. Sardinian goat's milk as source of bacteriocinogenic potential protective cultures. Food Contr. 25:309-320.

Semedo, T., M. A. Santos, M. F. S. Lopes, J. J. Figueiredo Marques, M. T. B. Crespo, and R. Tenreiro. 2003. Virulence factors in food, clinical and reference Enterococci: A common trait in the genus? Syst. Appl. Microbiol. 26:13-22.

Sharma, P., S. K. Tomar, P. Goswami, V. Sangwan, and R. Singh. 2014. Antibiotic resistance among commercially available probiotics. Food Res. Int. 57:176-195.

Shobharani, P., and R. Agrawal. 2011. A potent probiotic strain from cheddar cheese. Indian J. Microbiol. 51:251-258.

Silva, L. F. 2015. Diversidade e evolução da microbiota lática autóctone em queijo Muçarela de búfala e aplicação tecnológica dos isolados [Diversity and evolution of authoctonous lactic microbiota in water buffalo Mozzarella cheese and technological application of isolates]. Thesis. Department of Food Engineering and Technology, Sao Paulo State University, Sao Jose do Rio Preto, Brazil.
Silva, L. F., T. Casella, E. S. Gomes, M. C. L. Nogueira, J. D. D. L. Lindner, and A. L. B. Penna. 2015. Diversity of lactic acid bacteria isolated from Brazilian water buffalo Mozzarella cheese. J. Food Sci. 80:M411-M417.

Solieri, L., A. Bianchi, G. Mottolese, F. Lemmetti, and P. Giudici. 2014. Tailoring the probiotic potential of non-starter Lactobacillus strains from ripened Parmigiano Reggiano cheese by in vitro screening and principal component analysis. Food Microbiol. $38: 240-249$.

Tan, Q., H. Xu, Z. P. Aguilar, S. Peng, S. Dong, B. Wang, P. Li, T. Chen, F. Xu, and H. Wei. 2013. Safety assessment and probiotic evaluation of Enterococcus faecium YF5 isolated from sourdough. J. Food Sci. 78:M587-M593.

Tejedor Junco, M. T., M. Gonzalez-Martin, N. F. Rodriguez Gonzalez, and C. Gutierrez. 2015. Identification, antimicrobial susceptibility, and virulence factors of Enterococcus spp. strains isolated from camels in Canary Islands, Spain. Vet. Ital. 51:179-183.

Todorov, S. D., M. Botes, C. Guigas, U. Schillinger, I. Wiid, M. B. Wachsman, W. H. Holzapfel, and L. M. Dicks. 2008. Boza, a natural source of probiotic lactic acid bacteria. J. Appl. Microbiol. 104:465-477.

Todorov, S. D., and L. M. T. Dicks. 2008. Evaluation of lactic acid bacteria from kefir, molasses and olive brine as possible probiotics based on physiological properties. Ann. Microbiol. 58:661-670.

Todorov, S. D., L. Favaro, P. Gibbs, and M. Vaz-Velho. 2012. Enterococcus faecium isolated from Lombo, a Portuguese traditional meat product: Characterisation of antibacterial compounds and factors affecting bacteriocin production. Benef. Microbes 3:319-330.

Todorov, S. D., B. D. M. Franco, and I. J. Wiid. 2014. In vitro studies of beneficial properties and safety of lactis acid bacteria isolated from Portuguese fermented meat products. Benef. Microbes 5:351-366.

Todorov, S. D., D. N. Furtado, S. M. I. Saad, and B. D. G. M. Franco. 2011b. Bacteriocin production and resistance to drugs are advantageous features for Lactobacillus acidophilus La-14, a potential probiotic strain. New Microbiol. 34:357-370.

Todorov, S. D., D. N. Furtado, S. M. I. Saad, E. Tome, and B. D. G. M. Franco. 2011a. Potential beneficial properties of bacteriocinproducing lactic acid bacteria isolated from smoked salmon. J. Appl. Microbiol. 110:971-986.

Todorov, S. D., H. Prévost, M. Lebois, X. Dousset, J. G. LeBlanc, and B. D. G. M. Franco. 2011c. Bacteriocinogenic Lactobacillus plantarum ST16Pa isolated from papaya (Carica papaya)-From isolation to application: Characterization of a bacteriocin. Food Res. Int. 44:1351-1363.

Vankerckhoven, V., T. Van Autgaerden, C. Vael, C. Lammens, S. Chapelle, R. Rossi, D. Jabe, and H. Goossens. 2004. Development of a multiplex PCR for the detection of asa1, gelE, cylA, esp, and hyl genes in enterococci and survey for virulence determinants among European hospital isolates of Enterococcus faecium. J. Clin. Microbiol. 42:4473-4479.

Vinderola, G., C. Matar, and G. Perdigon. 2005. Role of intestinal epithelial cells in the immune effects mediated by gram-positive probiotic bacteria: Involvement of Toll-like receptors. Clin. Diagn. Lab. Immunol. 12:1075-1084.

Vinderola, C. G., and J. A. Reinheimer. 2003. Lactic acid starter and probiotic bacteria: A comparative "in vitro" study of probiotic characteristics and biological barrier resistance. Food Res. Int. 36:895-904.

von Mollendorff, J. W., S. D. Todorov, and L. M. Dicks. 2007. Factors affecting the adsorption of bacteriocins to Lactobacillus sakei and Enterococcus sp. Appl. Biochem. Biotechnol. 142:209-220.

Werner, G., T. M. Coqueb, C. M. A. P. Franzc, E. Grohmannd, K. Hegstade, L. Jenseng, W. Schaikh, and K. Weaveri. 2013. Antibiotic resistant enterococci-Tales of a drug resistance gene trafficker. Int. J. Med. Microbiol. 303:360-379.

Zhou, J. S., P. K. Gopal, and H. S. Gill. 2001. Potential probiotic lactic acid bacteria Lactobacillus rhamnosus (HN001), Lactobacillus acidophilus (HN017) and Bifidobacterium lactis (HN019) do not degrade gastric mucin in vitro. Int. J. Food Microbiol. 63:81-90. 